\title{
Impacts of FERC Order No. 2222 on Dairy Manure Processing in Wisconsin
}

\author{
Evan D. Erickson, Philip A. Tominac, and Victor M. Zavala* \\ Department of Chemical and Biological Engineering \\ University of Wisconsin-Madison, 1415 Engineering Dr, Madison, WI 53706, USA
}

\begin{abstract}
The agricultural practice of spreading dairy manure to fertilize crop fields leads to widespread air and water pollution, due to uncontrolled release of greenhouse gases, nutrients, and pathogens. The associated environmental and health impacts can be mitigated by deploying manure processing (MP) systems that can capture methane to produce electricity and that facilitate nutrient management. Unfortunately, electricity rates available to MP systems in the United States (US) provide limited economic incentives to promote their deployment. Recent policy enacted by the Federal Energy Regulatory Commission (Order 2222) enables distributed energy resource (DER) systems (such as MP systems) to participate in wholesale electricity markets. We present supply chain and market analyses in Wisconsin showing that this order can help activate an electricity bioeconomy that can help mitigating environmental and health impacts resulting from manure spreading. We estimate that this bioeconomy could generate up to $\$ 131$ million in revenue for dairy farms annually while averting $\$ 39$ million in greenhouse gas emissions and \$182 million in nutrient emissions.
\end{abstract}

Keywords: manure, air pollution, water pollution, bioeconomy, electricity markets.

Dairy farming in the United States (US) is a multi-billion dollar industry that provides essential food products (e.g., milk, cheese, ice cream, yogurt). Unfortunately, the millions of animals that this industry oversees generate a massive environmental footprint that affects air and water quality [1, 2]. Specifically, dairy manure is a carbon- and nutrient-rich (nitrogen and phosphorus) waste stream that is routinely used as fertilizer; this practice enables nutrient recycling but also leads to emissions of methane, ammonia, and nitrous oxide (greenhouse gases) and to nutrient accumulation in soils (manure nutrients are often imbalanced with crop needs). Nutrient accumulation promotes runoff to surface and groundwaters leading to ecosystem disruption (eutrophication and algae blooms). Processing manure in a scalable manner remains a grand societal challenge $[3,4,5]$.

Governments in the US and worldwide face increasing pressures to reduce air and nutrient pollution $[6,7,8,9,10]$. At the same time, farmers are seeking technologies that can open new revenue streams and hedge against pollution taxes [11, 12]. Communities and citizen organizations also recognize the threats to water systems by concentrated animal feeding operations (CAFOs) such as dairy

\footnotetext{
${ }^{*}$ Corresponding Author: victor.zavala@wisc.edu
} 
farms and support action to protect these valuable and shared resources [13, 14, 15, 16, 17]. Nutrient management is becoming an increasingly important issue due to the need to secure strategic phosphorus resources (which are essential for securing future food supplies).

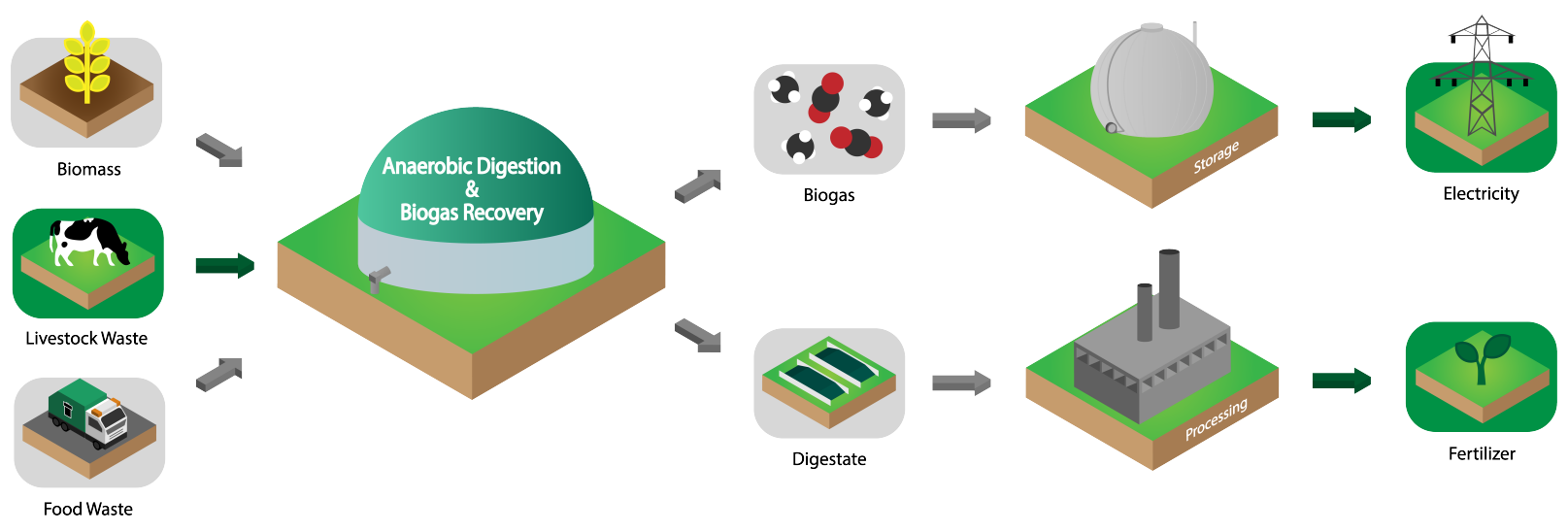

Figure 1: Bioenergy (electricity and biogas) can be generated from a variety of sources, including biomass, livestock manure, and food waste. In the pathway studied, we begin with livestock manure and recover biogas through the biochemical process of anaerobic digestion. Biogas can be stored to generate electricity on-demand for sale to the power grid. The remaining digestate can be further processed to recover nutrient-rich fertilizer products and can help achieve nutrient balancing.

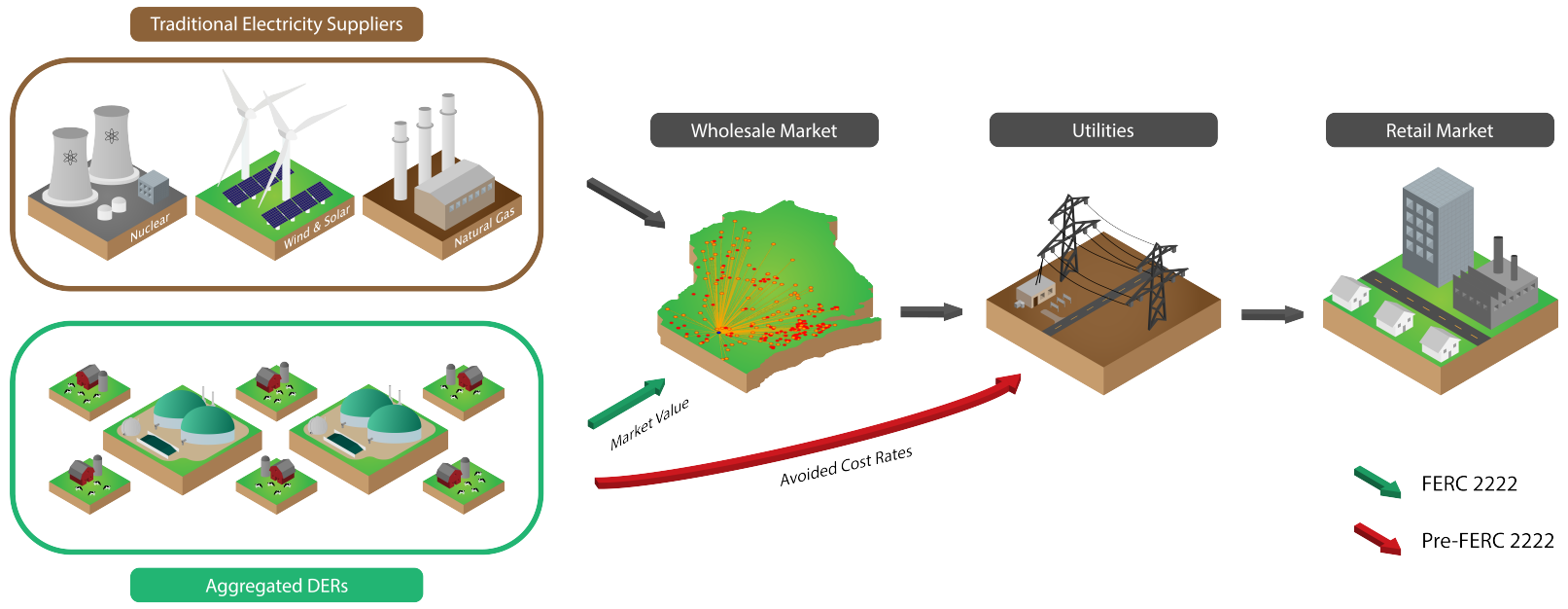

Figure 2: FERC-2222 allows distributed energy resources (DERs) to participate in wholesale electricity markets by allowing aggregations of DERs to bid as a collective. For an exploration into FERC policy and context in greater depth, see our Supplementary Information section.

Farmers can mitigate environmental impacts of manure by deploying manure processing (MP) systems that can generate value-added products [18]. Specifically, manure can be processed in an anaerobic digester to recover a phosphorus-rich digestate and a methane-rich gas mixture (biogas) [19] (see Figure 1). Digestate can be further processed into fertilizers and specialty chemicals such as struvite (a slow-release fertilizer), while the biogas can be used to produce electrical power (renew- 
able bioenergy) and this can be injected into the power grid. As expected, electricity revenues play a key role in promoting the deployment of MP systems [20]; unfortunately, electrical utilities offer avoided cost rates (usually 40 - 60 US/MWh) undercutting wholesale market prices [21, 22, 23, 24, 25, 26]. This explains explain why there are few anaerobic digestion systems installed in the US (there are only 273 on-farm units [27]) compared to other economies with developed renewables (e.g., Germany has nearly 9000 digesters in operation) [28]. The lack of MP infrastructure in the US hinders attempts to mitigate environmental impacts related to dairy farming.

The Federal Energy Regulatory Commission (FERC) governs energy markets in the US. FERC Order 2222 (issued September 2020) enacts a policy change that allows distributed energy resources (DERs) such as MP systems to participate in wholesale electricity markets [31] (see Figure 2). A detailed discussion of FERC-2222 is included as Supplementary Information. We explore economic effects that FERC-2222 can have on the 245 largest dairy farms in Wisconsin using a supply chain model. Our results indicate that FERC-2222 can activate a manure bioeconomy to recover electricity, biogas, and nutrients. We envision this bioeconomy providing a peak generation service; our results show economic viability at electricity prices exceeding 171.69 USD/MWh, with the potential to generate up to $\$ 131$ million in annual revenue for Wisconsin dairy farms, avert \$39 million in carbon emissions, and $\$ 182$ million in nutrient emissions. Figure 3 illustrates this bioeconomy and summarizes our findings.

\section{Results}

The MP systems that we study aim to exploit dynamics of wholesale electricity markets to maximize revenue. Here we introduce our results with a brief overview of the Midcontinent Independent System Operator (MISO), which operates day-ahead and real-time electricity wholesale markets for fifteen US states, including Wisconsin [32]. In this study, we focus on real-time prices; these prices are a complex function of power plant commitments and spatio-temporal variations in demand. Realtime prices are updated every 5 minutes and are highly volatile; moreover, they are typically higher during on-peak hours and lower during off-peak hours. We analyze different case studies that explore opportunities for manure processing (MP) systems to participate in these real-time electricity markets, with a focus on identifying price thresholds that make participation profitable (prices sufficient to activate a bioeconomy). Our analysis is based on a supply chain model (SCM) that captures transactions between dairy farms (which supply manure) technology providers (MP systems) transportation providers (manure haulers) and consumers of electricity (the real-time wholesale electricity market) and of other value-added products. The wholesale electricity market is captured as a single hub node.

MISO makes data available for real-time market prices on a daily basis, providing price indicators for daily, on-peak, and off-peak price values [34]. On-peak electricity prices are those occurring between 7:00 and 22:00 (EST) Monday to Friday; all other times are considered off-peak for the purposes of this indicator. For each of these three daily price values, the average, record low, and record high are provided. Important real-time market price indicators are shown for 2019 in Figure 4; note 


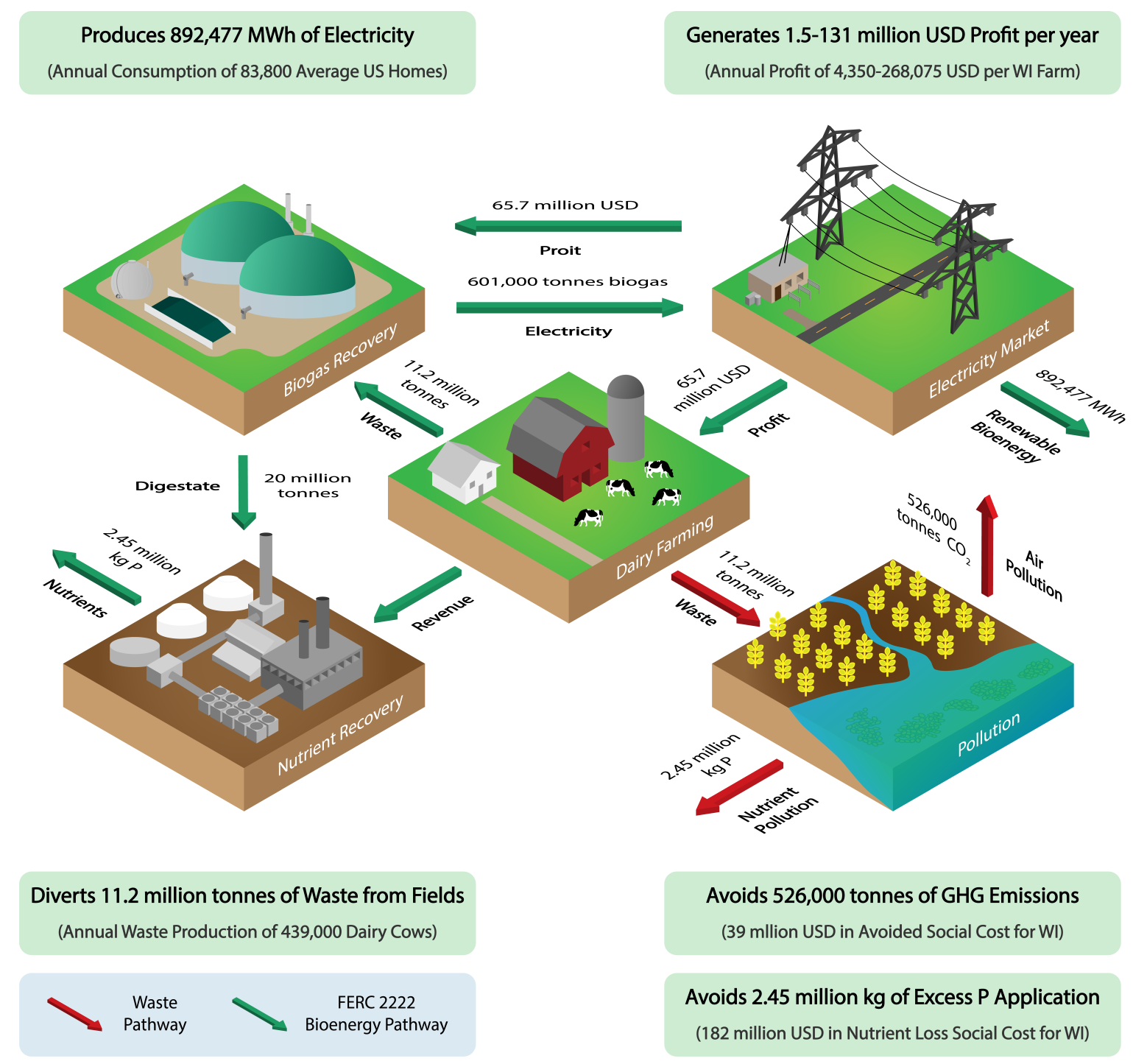

Figure 3: Livestock waste production has significant environmental impacts. Dairy farms can apply organic waste as direct fertilizer, but this contributes to environmental pollution and a global scale of nutrient loss. Alternatively, waste can be used to generate electricity from stored biogas and revenue to support nutrient recovery technologies for better phosphorus security. FERC-2222 incentivizes this bioenergy pathway; In the State of Wisconsin, we estimate that this policy change could generate substantial profit for manure processing systems, reduce carbon emissions, and mitigate nutrient waste.

that daily highs can achieve significant values (i.e., in the thousands of USD/MWh) and the lows can be negative (with a consumer being paid to use electricity to maintain grid stability). We treat these data as a set of real-time market price indicators. In our results, we present case studies at fixed price "snapshots" selected based on these indicators to show how FERC policy and price variation influence the viability of the bioeconomy.

Electricity produced through MP systems is expensive and thus average electricity prices will not support a bioeconomy; however, we anticipate that MP systems can generate revenue by participat- 
(A)

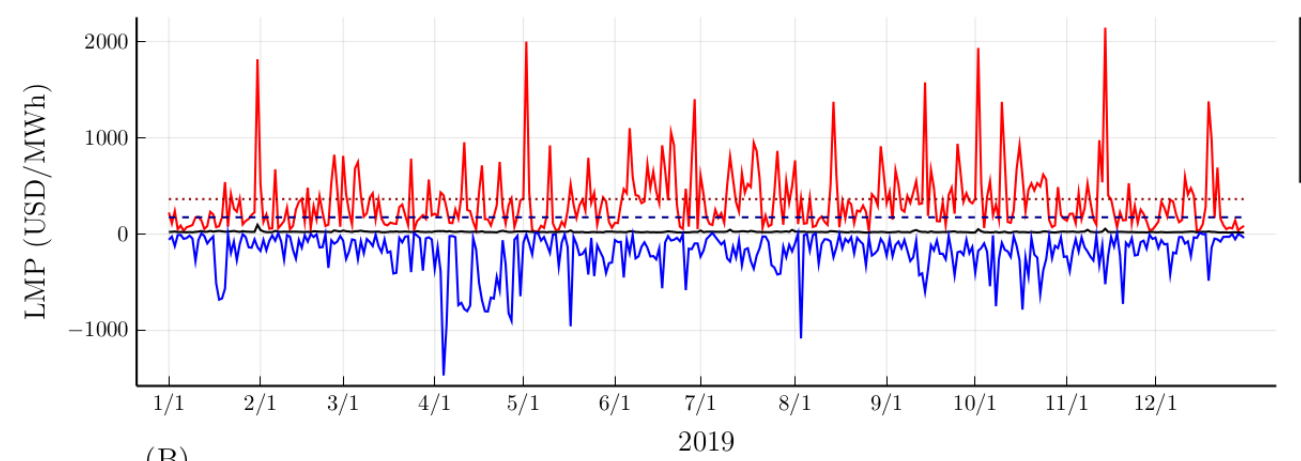

(B)

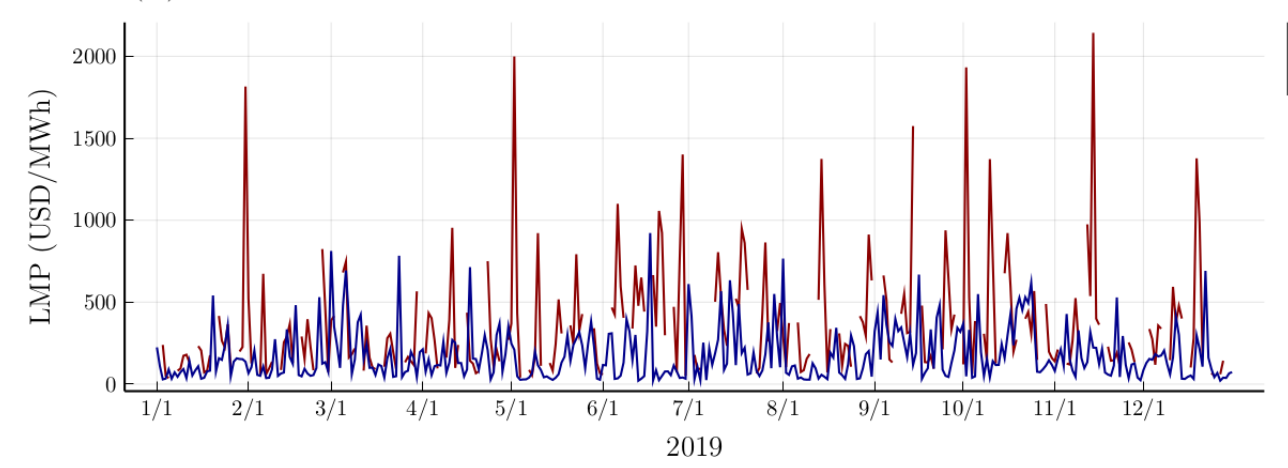

Figure 4: Electricity prices in the MISO vary significantly throughout a given day (A) between positive and negative extremes, but the daily average price stays relatively consistent. Prices can reach extreme values (B) driven by demand and the physics of the electrical grid, and the MISO reports on-peak and off-peak highs that demonstrate these extreme prices occur at any time. The horizontal lines in (A) indicate the 2019 annual average off-peak high price of 174.83 USD/MWh (dashed) and the average on-peak high of 363.71 USD/MWh (dotted).

ing as a peaking generator that stores biogas and responds strategically to price peaks in the real-time market. In Figure 4B we present daily on- and off-peak high price records; the average on- and offpeak high values over the course of the year are reflected on Figure 4A). The average off-peak high price is 174.83 (greater than our break-even threshold) and the daily price exceeded this value on 229 days (a higher daily price occurred on 63\% of days) in 2019. The 2019 on-peak average high price was 363.71 USD/MWh; the daily high price exceeded this value 127 days (35\%) suggesting there are relatively frequent opportunities to profit from price peaks on the real-time market. Our SCM analyses use these prices as snapshots with results compiled in Table 1.

The SCM studied has a market interpretation that helps reveal the inherent value of manure and value-added products as well as expected stakeholder revenues, costs, and profits. This market is analogous to (and thus compatible with) wholesale electricity markets operated by other ISOs in the US. The SCM incorporates techno-economic models that capture operating costs (electricity generation costs) of MP systems; such models are based on technology performance data obtained from $\mathrm{Hu}$ et al. [33]. More details are provided in the Methodology section.

Using the SCM we estimate that in a post-FERC-2222 setting, a real-time wholesale electricity 
Table 1: SCM results for selected snapshot prices, including total combined dairy farm (CAFO) and MP system profits, total manure processed and electricity generated, and the single longest transportation distance at the given price level.

\begin{tabular}{lrrrrr}
$\begin{array}{c}\text { Snapshot price } \\
\text { (USD/MWh) }\end{array}$ & $\begin{array}{c}\text { CAFO } \\
\text { profit (USD) }\end{array}$ & $\begin{array}{c}\text { MP profit } \\
\text { (USD) }\end{array}$ & $\begin{array}{c}\text { Manure processed } \\
\text { (tonne) }\end{array}$ & $\begin{array}{c}\text { Electricity } \\
\text { generated } \\
\text { (MWh) }\end{array}$ & $\begin{array}{c}\text { Longest } \\
\text { transport } \\
\text { distance (km) }\end{array}$ \\
\hline 171.69 & 0 & 0 & $5,907,962$ & 470,060 & 0 \\
174.83 & $1,065,981$ & 444,081 & $6,200,209$ & 493,312 & 1.5 \\
363.71 & $65,678,390$ & $65,661,407$ & $9,519,916$ & 757,441 & 87.4 \\
861.79 & $214,061,309$ & $330,985,212$ & $11,217,129$ & 892,477 & 275.8 \\
\hline
\end{tabular}

price of 171.69 USD/MWh is sufficient to achieve economic viability for on-site MP systems. This critical threshold defines the break-even price point at which MP systems will start producing electricity, but where manure transportation is still cost-prohibitive. This case is illustrated in Figure 5, which highlights SCM responses to various electricity price points. Figure 5A (a SCM snapshot of the MP supply chain operating at an electricity price of 171.69 USD/MWh) shows that dairy CAFOs with on-site MP systems are active, but there is no incentive to transport manure over any distance, and no profit is generated. Approximately 470,060 MWh of electricity are produced, processing 5.9 million tonnes of manure. We note that the average annual household electricity consumption in the US in 2019 was 10.65 MWh, so the bioeconomy provides for the equivalent of 44,137 residences.

We next examine a price snapshot at the average off-peak high rate of 174.83 USD/MWh. Most notably, this case results in a profit around 1 million USD to the 245 CAFOs and 444 thousand USD to the $120 \mathrm{MP}$ systems, and importantly, the higher price provides the incentives required to transport manure at least $1.5 \mathrm{~km}$ to MP-equipped sites. This case is not included in Figure 5 (transport at 1.5 $\mathrm{km}$ or less does not resolve on the map at the given scale) but the results are included in Table 1.

Resolving the SCM at the average on-peak high snapshot price of $363.71 \mathrm{USD} / \mathrm{MWh}$, we observe that CAFO and MP profits increase to about 65 million USD each (131 million in profit combined) achieving the processing of 9.5 million tonnes of manure, and producing 757,441 MWh of electricity (71,121 residences). Notably, this price creates an incentive to transport manure at most $87.4 \mathrm{~km}$ for processing, revealing (see Figure 5B) that careful peaking practices support that transport of manure from relatively densely clustered CAFOs in Eastern Wisconsin for processing. Incentivizing manure transport in this bioeconomy is key, as this facilitates processing and nutrient movement (e.g., from nutrient-rich areas to nutrient-deficient areas).

Our final snapshot price is determined as the minimum incentivizing the transport and processing of $100 \%$ of the available manure supply, calculated at 861.79 USD/MWh based on SCM analysis. First, we observe that this extends the pattern observed in the previous case; manure transport extends as far as $275.8 \mathrm{~km}$ across the state, primarily to the West. This result points to existing limitations within the MP design: there is insufficient capacity in our MP design in Eastern Wisconsin to process the manure produced there, and transport costs prohibit the movement of manure to areas with additional capacity. This case demonstrates that only extreme peak prices could support the 
given layout, but also suggests that reorganizing the locations of the $120 \mathrm{MP}$ installations based on minimizing transportation costs subject to the locations of the CAFOs could result in a significant decrease in the required electricity price. At a 100\% manure processing rate (all 11.2 million tonnes), MP systems can produce 892,477 MWh of electricity $(83,800$ residences) and almost double that of the break-even outcome. We include the profit values in this case, but note that they are excessive, and represent the SCM result in which every MWh produced can be sold at the determined rate.

Our SCM analyses show that manure transportation costs are significant, and create an impediment to MP system viability. However, peak electricity prices are sufficient to incentivize transportation over reasonable distances. Moreover, using transport and capacity (where MP units should be built, and at what capacity) as guidelines for MP system location would like reduce the price peak threshold required to achieve 100\% manure processing. Dairy farm electricity generation potential is small on the state scale (at 100\% utilization providing about $1.4 \%$ of the total annual state electricity demand) our results suggest the peaking practice would allow CAFOs to process most or all of their manure to produce electricity. MP system design and facility location could reduce the viable price incentives that we have determined, facilitating expansion of manure transport and collection to additional dairy farms, increasing generation capacity.
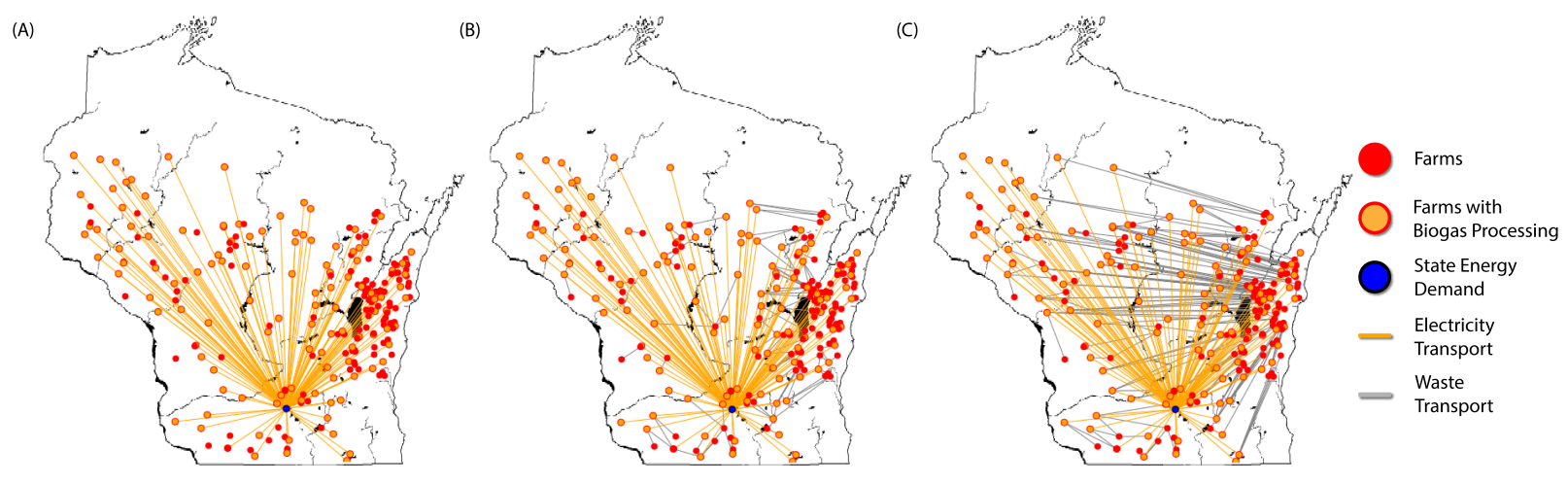

Figure 5: Incentives and supply chain outcomes post-FERC-2222. The market is (A) dry for electricity prices less than $171.69 \mathrm{USD} / \mathrm{MWh}(\mathrm{B})$ is active and supports transportation up to $87.4 \mathrm{~km}$ at the average on-peak price of $363.71 \mathrm{USD} / \mathrm{MWh}$, and $(\mathrm{C})$ has a minimum viable electricity price of 861.79 USD/MWh required to process $100 \%$ of the manure produced, with a maximum transport requirement of $275.8 \mathrm{~km}$.

We also use the SCM to compare outcomes in a pre-FERC-2222 setting with those in a post-FERC2222 setting. In this case, with results illustrated in Figure 6, we compare the pre-FERC dairy MP network operating under a conservative avoided cost electricity rate of $50 \mathrm{USD} / \mathrm{MWh}$ (electrical utilities' avoided costs rates are usually on the order of 40 - 60 USD/MWh [22]) with a post-FERC dairy MP DER operating at the 2019 off-peak high electricity price of 174.83 USD/MWh. Figure 
6A shows that pre-FERC-2222, no waste is transported and no electricity is produced, while Figure $6 \mathrm{~B}$ we observe bioeconomy activation with significant (but not complete) utilization of the available manure supply.

Pre-FERC-2222 electrical utilities absorb the majority share of the final value of electricity. Utilities normally purchase from suppliers on the real-time market, but pre-FERC-2222 could purchase directly from DERs at sub-market (avoided cost) prices. Notably, this did create incentives for utilities to work with DERs, but creates no incentive for DERs to produce electricity (the offered price fails to cover the costs of generation). The avoided cost price policy in the pre-2222 market is a noncompetitive practice; utility prices offered to DERs systems undercut market prices [22]. Due to the nature of these pre-2222 policies, dairy farmers were unable to respond to incentives in electricity markets, and had little incentive to produce electricity. Under FERC-2222 and new aggregation policies allowing DERs to enter electricity markets, these economic barriers are removed, MP DERs have access to real-time markets, and have no incentive to operate in the avoided cost dynamic.
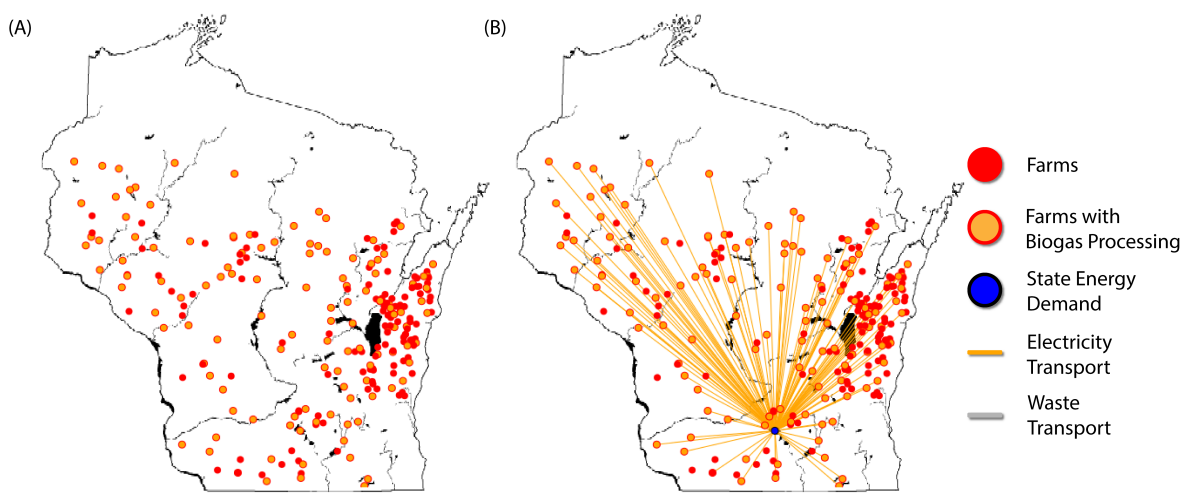

Figure 6: Farms operating in (A) the pre-2222 avoided-cost market at a retail price of 50 USD/MWh paid by utility companies and in (B) the post-2222 real-time market at a wholesale price of 174.83 USD/MWh. We observe no market activation pre-2222 at the avoided-cost rate because it is not sufficient to cover the cost of electricity production. Post-2222, opportunities on the MISO markets create incentives sufficient to activate a bioeconomy that produces electricity from manure.

The SCM provides insights on potential product prices, revenues, and profits generated by the bioeconomy activated by FERC-2222. In our post-FERC-2222 cases (documented in Table 1) we observe that the bioeconomy can lead to manure prices that are directly coupled to electricity prices (manure becomes a valuable resource). In our 174.83 USD/MWh case, manure prices across the state varied between 0.00 and $0.25 \mathrm{USD} /$ tonne. Since we assume manure is offered by farmers for free, any positive price is the result of the value of the electricity that can be produced from it. By contrast, under a real-time electricity price of $363.71 \mathrm{USD} / \mathrm{MWh}$ the value of manure can reach up to 15.28 USD/tonne. Conversely, at any electricity price below 171.69 USD/MWh, MP systems do not 
participate in electricity markets, and manure prices are uniformly zero across the state (providing no value). These positive manure prices indicate that dairy farmers would generate revenue in the bieconomy. For example, In the 174.83 USD/MWh case, individual farms earned an average annual profit of 4,350 USD (with a maximum of 22,456 USD) demonstrating that FERC-2222 creates value.

Our case studies focus on specific price snapshots; assuming that DERs are able to sell electricity consistently at MISO average off-peak high prices (i.e., by targeting sales and following price dynamics) the potential annual revenue is on the order of 1.51 million USD, including profits to both CAFOs and MP systems. This provides a conservative baseline estimate for profit; DERs can profit at greater rates if they are able to target sales to peak market prices, which can spike significantly during onpeak demand hours. These peaks are less frequent, but offer greater incentives: for comparison, the MISO average 2019 on-peak high price was 363.71 USD/MWh [34]. Selling at this rate, DERs could generate revenue on the order of 131 million USD (about 65.7 million profit earned in total each by CAFOs and the MP systems) annually, representing an average profit of 268,075 USD/CAFO, and 547,178 USD/MP system.

We next address the particular scenario of negative electricity prices. Figure 4 shows that realtime prices can also spike to large negative values. This occurs when active electricity supply is in excess of consumer demand; the grid can only tolerate the excess to a certain extent, at which point operators will lower the price to encourage consumption to balance the grid. Importantly, this means market stakeholders can be paid to consume electricity. While we do not present a case study of this phenomenon, MP systems can also consume the electricity as part of a combined heat and power system (CHP) suggesting that MP systems should buy electricity when prices are negative (use the grid to run the CHP system) and store biogas to sell electricity when prices peak (a practice known as hedging). Negative electricity prices are secondary advantage to being classified as a DER on the real-time market.

FERC-2222 allows MP systems to compete on the same level as traditional electricity providers (e.g., power plants); however, MP systems still occupy a small share of the market. MP systems can participate in the markets as a peaking resource, similar to natural gas-fired power plants. A detailed techno-economic analysis is required to determine the amount of electricity a DER could anticipate purchasing at negative prices, and how much could be produced for sale as a peaking service.

The bioeconomy can help mitigate environmental impacts associated with manure spreading (GHG and nutrient emissions). Aguirre-Villegas and Larson [1] surveyed GHG emissions from fieldapplied manure (dominated by methane and nitrous oxide emissions). Based on CAFOs of similar size, we estimate that electrical market incentives can prevent the emission of $2.69 \times 10^{5}$ tonnes of $\mathrm{CO}_{2}$ equivalents that would result from field spreading. At the US social cost of carbon (SCC, valued at $51 \mathrm{USD} /$ tonne $\mathrm{CO}_{2}$-eq) this reduction is worth 12.4 million USD annually [35, 36].

Obtaining electricity through manure avoids GHG emissions associated with fossil energy sources. In $2019,42 \%$ of the electricity in Wisconsin was produced from coal (most of this was imported from other states) [37]. The U.S. Energy Information Administration estimates that for every kilowatt of electricity generated from coal, 2.21 pounds of $\mathrm{CO}_{2}$ are emitted [38]. Though obtained from renewable sources, bioenergy is similar in many respects to natural gas. Assuming bioenergy has a comparable rate of emissions to natural gas ( 0.41 tonne of $\mathrm{CO}_{2} / \mathrm{MWh}$ ) there is a net emissions savings of 
0.59 tonne/MWh compared to coal. In the case where our 245 CAFOs process $100 \%$ of their manure for electricity $\left(1.42 \%\right.$ of annual state demand) this avoids $5.26 \times 10^{5}$ tonnes of $\mathrm{CO}_{2}$. At the current SCC, this represents annual social savings of 26.8 million USD.

Anaerobic digestion of manure provides a first step for subsequent processing to produce stable, concentrated fertilizers that can be sold to generate additional revenue and to facilitate nutrient management. More importantly, this can reduce excess application of nutrients that result from direct manure spreading. Sampat et al. quantify the economic loss associated with excess field-applied phosphorus (i.e., in excess of crop needs) [39]. Using corn (the dominant grain crop in Wisconsin) and crop nutrient requirements from Kissel and Harris [40], we estimate that the 11.2 tonnes of manure produced by the 245 largest CAFOs would result in 2.45 million $\mathrm{kg}$ excess phosphorus applied (i.e., by applying manure to cornfields at a rate meeting its nitrogen requirements). Using the cost analysis of Sampat et al., this equates to 182 million USD/year in avoided social cost due to phosphorus. This cost can potentially be averted under the bioeconomy activated by FERC-2222, as this can help create incentives to deploy nutrient recovery technologies such as solid/liquid separation, ultrafltration, granulation, and struvite production.

\section{Discussion}

Manure spreading on crop fields presents a significant environmental threat and a lost economic opportunity. Manure processing for electricity generation is an economic opportunity that reduces the carbon and phosphorus footprints of dairy farming. Under FERC Order 2222, US dairy farms gain important protections (as aggregate DERs) allowing them to participate in wholesale electricity markets, and a significant price incentive to pursue this technology pathway. Electricity revenues also create opportunities to pursue downstream digestate processing. The manufacture of stable, concentrated fertilizers is a first step to enhancing nutrient cycling and phosphorus security in the US. The electricity produced is renewable, and displaces fossil sources with quantifiable emissions reductions.

While FERC-2222 is primarily targeted towards improving access to wholesale electricity markets for smaller wind and solar power installations, it creates opportunities for dairy farms as DERs; we observe that the potential revenues available stand to change the industry outlook on manure management and processing. Under this new policy, manure becomes a valuable asset. Our results point to manure processing as the first element of a larger supply chain culminating in the production of a variety of fertilizer products, and from which electricity is a valuable by-product; FERC-2222 provides the necessary policy changes to activate this market.

By exposing MP systems to wholesale market electricity prices, FERC-2222 can help activate this bioeconomy and open new revenue opportunities for dairy farms. We demonstrate the impacts of FERC-2222 on the state of Wisconsin, and only for the largest dairy farms; the policy implications for environmental health and phosphorus security could be significantly greater on the national scale, especially if the new infrastructure can find ways to include smaller dairy farms. FERC-2222 creates incentives that simultaneously increase economic welfare and mitigate environmental impacts, and 
represents an important step in the support of renewable energy, in addressing environmental issues, and in nutrient security.

\section{Methods}

\section{Supply Chain Model}

We construct a supply chain model (SCM) that includes the 245 largest CAFOs in the State of Wisconsin to explore the economic impacts of FERC-2222 [41]. Here, we assume that only 120 of these CAFOs are equipped with MP systems (all CAFOs pay the MP systems for the processing service, but CAFOs without MP systems on-site also pay for manure transportation). The SCM framework used was recently proposed by Tominac and Zavala [42] and is capable of capturing transactions of different products (e.g., manure), derived products (e.g., biogas, electricity, carbon emissions), and transformation pathways between products (e.g., MP systems). This modeling approach sees the supply chain as a collection of independent profit-maximizing stakeholders that offer or request products and services to an agent that coordinates transactions. This coordinated market framework is consistent with coordinated electricity markets that are under current operation in the US (such as that operated by MISO). This framework helps reveal inherent values of product streams (e.g., manure) and provides a coherent mechanism to remunerate stakeholders. All case study data scripts needed to reproduce the results are available at https://github.com/zavalab/JuliaBox/tree/master/ FERC2222Cases.

Market coordination is a management strategy that is used to determine transactions between a collection of stakeholders (who collectively form a market for products and services). In this strategy, an independent system operator (ISO) acts as an intermediary between stakeholders (they do not negotiate amongst themselves) to determine an optimal set of transactions that creates the greatest total collective profit. The ISO coordinates stakeholders by collecting bidding information (as in an auction process) and clears the market by solving a supply chain management problem (a resource allocation problem). The ISO does not have a stake in the market (does not absorb or divert revenue streams from the market). The bidding and clearing processes allow the market to reach an outcome quickly, hence their use in electricity markets, where supplier responses to changes in consumer demand must be rapid. Moreover, the allocations resulting from coordination have been proven to represent a competitive equilibrium. This result frames the coordination outcome as an optimal solution to the process of peer-to-peer negation involving all stakeholders. Coordination is viewed as a market catalyst that saves time without sacrificing competitiveness.

In our SCM, stakeholders fall into one of four classes: suppliers (who sell products) consumers (who buy them), technology providers (who transform products from one form to another), and transportation providers (who move products from one location to another). Each of these stakeholders has a bid parameter representing its price threshold to sell, buy, process, or move a product (i.e., in USD/unit weight) and a capacity parameter restricting the amount that can be sold, bought, processed, or transported. The ISO uses this information to determine how much product will be exchanged in each transaction (this is called an allocation). 
We represent 245 dairy CAFOs as suppliers of manure, and a $246^{\text {th }}$ supplier representing collective electricity generation in the State of Wisconsin (competing with MP systems). We assume that CAFOs offer manure for free; the electricity supplier bid is set to various wholesale market prices in order to explore the impact of price variation. These suppliers are collectively indexed in the set $i \in \mathcal{G}$ each with a bid parameter $\alpha_{i}^{g} \in \mathbb{R}_{+}$, capacity parameter $\bar{g}_{i} \in \mathbb{R}_{+}$, and allocation $g_{i} \in \mathbb{R}_{+}$. The 120 MP systems available are represented as a set of technology providers $m \in \mathcal{M}$ with bid processing cost $\alpha_{m}^{\xi} \in \mathbb{R}_{+}$, processing capacity parameter $\bar{\xi}_{m} \in \mathbb{R}_{+}$, and allocation $\xi_{m} \in \mathbb{R}_{+}$. We include a single consumer that requests electricity from the MP systems. This represents the wholesale electricity market and is captured as a single hub location. The capacity of this hub is consistent with annual electricity consumption rates in Wisconsin and is indexed as $j \in \mathcal{D}$ with bid parameter $\alpha_{j}^{d} \in \mathbb{R}_{+}$, capacity parameter $\bar{d}_{j} \in \mathbb{R}_{+}$, and allocation variable $d_{j} \in \mathbb{R}_{+}$. Waste and electricity transport are both indexed in the set $l \in \mathcal{L}$ (which captures the supply chain disposition of farm locations) with bids $\alpha_{l}^{f} \in \mathbb{R}_{+}$, capacities $\bar{f}_{l} \in \mathbb{R}_{+}$, and allocation variables $f_{l} \in \mathbb{R}_{+}$. Using these parameters and variables, the optimization problem is formulated as in (1).

$$
\begin{gathered}
\max _{s, d, f, \xi} \sum_{j \in \mathcal{D}} \alpha_{j}^{d} d_{j}-\sum_{i \in \mathcal{G}} \alpha_{i}^{g} g_{i}-\sum_{l \in \mathcal{L}} \alpha_{l}^{f} f_{l}-\sum_{m \in \mathcal{M}} \alpha_{m}^{\xi} \xi_{m} \\
\text { s.t. } \sum_{i \in \mathcal{G}_{n, p}} g_{i}+\sum_{l \in \mathcal{L}_{n, p}^{\text {in }}} f_{l}+\sum_{m \in \mathcal{M}_{n, p}^{\text {gen }}} \gamma_{m, p} \xi_{m} \\
\sum_{j \in \mathcal{D}_{n, p}} d_{j}+\sum_{l \in \mathcal{L}_{n, p}^{\text {out }}} f_{l}+\sum_{m \in \mathcal{M}_{n, p}^{\text {con }}} \gamma_{m, p} \xi_{m}, \quad(n, p) \in \mathcal{N} \times \mathcal{P},\left(\pi_{n, p}\right) \\
g_{i} \leq \bar{g}_{i}, \quad i \in \mathcal{G} \\
d_{j} \leq \bar{d}_{j}, \quad j \in \mathcal{D} \\
f_{l} \leq \bar{f}_{l}, \quad l \in \mathcal{L} \\
\xi_{m} \leq \bar{\xi}_{m}, \quad m \in \mathcal{M}
\end{gathered}
$$

The objective function(1a) maximizes the total welfare, which is given by the total demand served and the total supply, transformation, and transport costs. Tominac and Zavala [42] have used duality theory to show that maximizing the total welfare is equivalent to maximizing total stakeholder profit. The constraint (1b) ensures that all product flows are balanced; i.e., any products supplied to the market are consumed by another stakeholder, accounting for any product transportation or transformation. These balances hold at every geographical location $n \in \mathcal{N}$ and for each product $p \in \mathcal{P}$. The dual variable (shadow price) of each of these constraints $\left(\pi_{n, p}\right)$ is the clearing price of product $p$ at the location node $n$. We use subsets to simplify the notation for transport: $\mathcal{L}_{n, p}^{i n}$ is the subset of transport providers $l \in \mathcal{L}$ who deliver product $p$ to node $n$, and similarly $\mathcal{L}_{n, p}^{\text {out }}$ are those who transport $p$ away from $n$. We use a similar notation for product transformation with the set $\mathcal{M}_{n, p}^{g e n}$ used to represent those technologies producing a product $p$ at node $n$ and $\mathcal{M}_{n, p}^{c o n}$ those technologies consuming it. The parameters $\gamma_{m, p}$ are the input and output yield coefficients for each technology (e.g., how many units of electricity can be produced/unit of manure). Constraints (1c) to (1f) are the 
capacity limitations for each stakeholder, including dairy farms, waste or electricity transporter, MP systems, and the electricity consumer.

A key benefit of the SCM is that it replicates clearing mechanisms used in wholesale electricity markets; as such, the outcomes of the model are consistent with the properties of electricity markets. Specifically, the clearing prices $\pi_{n, p}$ are determined in a similar way to prices in electricity markets, and have the same interpretation (i.e., the inherent value of each product and at each geographical location). These prices can help discover inherent value for products (e.g., manure). These prices also provide a mechanism to remunerate stakeholders, help us understand how revenue is distributed among stakeholders, and determine stakeholder profits. For instance, even if manure is offered at a zero cost, it generates value in the market and thus dairy farmers are remunerated accordingly based on the clearing price for manure.

\section{Modeling FERC Order 2222}

In the pre-2222 market setting, MPs were only able to sell electricity to utilities at their offered rates. In the post-2222 setting, MPs are able to sell electricity in wholesale markets at going market prices. To represent this structural change, we incorporate an additional technology in our pre-2222 case that acts as a barrier between the electricity consumer (Wisconsin market demand) and the MP systems. This technology represents utilities in the pre-2222 system; it does not perform conversion on the electricity produced by MP systems, but adds an intermediary bid that absorbs revenue (i.e., the utility sells the electricity at the market price, absorbs most of its value, and pays the avoided cost to the MPs). Notably, this makes the MPs less competitive in the market, because their operating costs are greater than the avoided cost that the utility pays them. In other words, they are less competitive because the consumer price for electricity (utility cost plus MP cost) is greater than the market price for electricity purchased from conventional fossil-based suppliers.

In our study of FERC-2222 we make two simplifications in our model. First, we collect all traditional fossil-based suppliers into one stakeholder to represent their sales to the power grid. The postFERC market emphasizes competition between traditional energy providers and renewable DERs, with pre-2222 policy putting MP systems at a competitive disadvantage. This aggregate supplier bid sets the electricity price for the consumer in the SCM (i.e., determining the electricity price on the wholesale market. Its capacity is equal to the state's annual demand). This formulation simplifies our model, and allows us to focus on policy interpretations. Our second simplification is our representation of Wisconsin electricity demand using a single consumer. Real electricity markets have multiple hubs from which electricity is distributed to end consumers, with prices tracked at specific nodes in the power grid. In the case of MISO, there are eight hubs and more than 300 nodes where prices are determined [34]. Our simplification represents electricity prices within Wisconsin at a single hub price. We model a single electricity price in order to avoid obscuring our primary result. FERC-2222 improves how MP systems (DERs) compete in the wholesale market and could affect the price the market operator pays to source electricity for its retail customers. Modelling a single demand means that we do not observe any variation in consumer demand or pricing, but this does not impact the qualitative nature of our results with respect to FERC policy. 


\section{Importance of the FERC-2222 Policy}

In September 2020, the US Federal Energy Regulatory Commission (FERC) released Order No. 2222, which significantly changed the market structure of energy grids. Prior to this legislation, local system operators typically enforced minimum capacity and performance requirements on suppliers looking to sell energy in wholesale markets to the exclusion of DERs. In some cases, DERs were allowed to sell electricity via contracts called power purchase agreements (PPAs) [43], but most utilities negotiated with DERs directly (outside the wholesale market structure) and followed a practice of paying DERs at their avoided cost. The avoided cost typically ranges between 40 and 60 USD/MWh (varying regionally) and is also significantly less than average wholesale prices [23, 24, 25, 26]. This structure proved insufficient to cover the costs of biogas production, and meant few DERs could operate within this framework [26]. A detailed discussion on the FERC-2222 order is provided in the supplemental information.

Under FERC-2222, system operators can still mandate minimum participation requirements, but must allow DERs and other small-scale renewable energy producers (including bioenergy-producing farms) to aggregate to meet these requirements [31,44]. Aggregation provides an efficient way to organize DERs in an energy market. The aggregated DER bids into the wholesale market on behalf of its member DERs, which then individually commit electricity to the aggregate supply bid [45].

This change creates stronger incentives for DERs, and allows them to compete on equal footing with traditional energy providers (e.g. coal, nuclear, and natural gas) in wholesale markets. Subsequent orders, including FERC Order No. 2222-A in March 2021 [46] and Order No. 2222-B in June 2021 [47], have sought to clarify the original rule, and highlights that the change is still being refined by policymakers and stakeholders. We present a more detailed breakdown of this policy and its history in our supplementary information.

\section{Techno-Economic Data}

The Wisconsin biogas recovery market specifications are adapted from $\mathrm{Hu}$ et al. [33], including biogas system specifications (unit locations and sizes), the disposition of dairy CAFOs, and the annual production rates of organic waste. Our model contains 245 potential participating farms, which reflects the number of concentrated animal feeding operations (CAFOs) in the state. Farm locations reflect their physical locations within the state. We focus our analysis on only large animal operations because their revenue streams are larger and more reliable, increasing the probability that investing in biogas recovery would be feasible. These CAFOs also have a larger environmental impact than smaller farms.

Our model also contains 120 combined waste storage and processing facilities (including both digestion and biogas recovery). Their locations reflect the optimal placement found by $\mathrm{Hu}$ et al. who placed instances of eight different types of technology providers across the state (differentiated based on capacity, operating cost, and stoichiometric efficiency). Cost estimates include operation and maintenance of the anaerobic digestion system, screw press, and biogas cleaning, as well as the technology investment with an annualization rate of 20 years. Total operating costs for these simulated technologies range between 171.69 and 294.28 USD/MWh. 
For the purposes of this study, we model all 120 technology providers in the state model with the most efficient specifications (and the lowest bid) to achieve the maximum market activation during price peaks. We note again that there are only 34 active agricultural digesters in the state, so our design explores one potential network. Deeper analysis into technology specifications would inform which processing systems to construct and operate to maximize the opportunity of biogas recovery under post-2222 market policy.

Our electrical demand node is centered at Madison, the state capital, as is the collective conventional grid supplier. State demand capacity is 62,774,299 MWh/year, representing the state's net generation in 2019 reported by the US Energy Information Administration (EIA) [48]. Based on the difference between the minimum cost for efficient processing, and the traditional below-marketvalue contract prices, we design an intermediary (also centered at Madison) that enacts a fee of 124.83 USD/MWh on all farm-produced energy. This simulates the effect of utilities offering an avoided cost rate of $50 \mathrm{USD} / \mathrm{MWh}$ to renewable DERs, while the difference between this value and the market price is obtained as revenue by the utility (i.e., the avoided cost of buying on the market).

The SCM assumes optimal economic behavior for all farms: if the costs of biogas recovery are not met by the price offered, the farms will not produce electricity in our simulated market. However, there may be real-world situations where farms face competing incentives and are willing to accept less than the market value for their bioenergy. For example, the amount of manure that can be applied to crop fields is regulated in some regions [4], so farms may choose to produce bioenergy at a loss to avoid more extreme penalties.

\section{References}

[1] Horacio A. Aguirre-Villegas and Rebecca A. Larson. Evaluating greenhouse gas emissions from dairy manure management practices using survey data and lifecycle tools. Journal of Cleaner Production, 143:169-179, 2017. URL: https://www.sciencedirect. com/science/article/pii/s0959652616321953, doi:https://doi.org/10.1016/ j.jclepro.2016.12.133.

[2] Dave Chadwick, Sven Sommer, Rachel Thorman, David Fangueiro, Laura Cardenas, Barbara Amon, and Tom Misselbrook. Manure management: Implications for greenhouse gas emissions. Animal Feed Science and Technology, 166-167:514-531, 2011. Special Issue: Greenhouse Gases in Animal Agriculture - Finding a Balance between Food and Emissions. URL: https : / / wWw.sciencedirect.com/science/article/pii/s0377840111001556, doi:https: //doi.org/10.1016/j.anifeedsci.2011.04.036.

[3] Bo Sun, Linxiu Zhang, Linzhang Yang, Fusuo Zhang, David Norse, and Zhaoliang Zhu. Agricultural non-point source pollution in china: causes and mitigation measures. Ambio, 41(4):370-379, 2012. doi:10.1007/s13280-012-0249-6. 
[4] U.S. Environmental Protection Agency. Agriculture nutrient management and fertilizer. Accessed 2021/05/06. URL: https://www.epa.gov/agriculture/ agriculture-nutrient-management-and-fertilizer.

[5] DH Mueller, RC Wendt, and TC Daniel. Phosphorus losses as affected by tillage and manure application. Soil Science Society of America Journal, 48(4):901-905, 1984. doi:10.2136/ SSSAJ1984.03615995004800040040X.

[6] Dana Cordell and Stuart White. Peak phosphorus: clarifying the key issues of a vigorous debate about long-term phosphorus security. Sustainability, 3(10):2027-2049, 2011. doi:10.3390/ su3102027.

[7] Dana Cordell and Stuart White. Sustainable phosphorus measures: strategies and technologies for achieving phosphorus security. Agronomy, 3(1):86-116, 2013. doi:10.3390/ agronomy 3010086 .

[8] Mengqiu Wang, Chuanmin Hu, Brian B. Barnes, Gary Mitchum, Brian Lapointe, and Joseph P. Montoya. The great atlantic sargassum belt. Science, 365(6448):8387, 2019. URL: https://science.sciencemag.org/content/365/6448/83, arXiv:https://science.sciencemag.org/content/365/6448/83.full.pdf, doi:10.1126/science.aaw7912.

[9] U.S. Environmental Protection Agency. Northern gulf of mexico hypoxic zone. Accessed 2021/05/10. URL: https://www.epa.gov/ms-htf/ northern-gulf-mexico-hypoxic-zone.

[10] European Space Agency. Algal bloom in the baltic sea. Accessed 2021/05/10. URL: https://earth.esa.int/web/earth-watching/environmental-hazards/ content/-/article/algal-bloom-in-the-baltic-sea.

[11] Warren A Braunig. Reflexive law solutions for factory farm pollution. NYUL Rev., 80:1505, 2005.

[12] American Farm Bureau Federation. Farmers for a sustainable future: Sustainability facts. Accessed 2021/06/14. URL: https: / /www. fb.org/land/fsf.

[13] Clean Lakes Alliance. What we do. Accessed 2021/04/27. URL: https://www . cleanlakesalliance.org/what-we-do/.

[14] North American Laek Management Society. Our mission. Accessed 2021/06/10. URL: https: //www.nalms.org/our-mission/.

[15] Healing Our Waters Great Lakes Coalition. Reducing polluted runoff in the great lakes. Accessed 2021/06/10. URL: https://healthylakes.org/lake_issues/ reducing-polluted-runoff/.

[16] US Environmental Protection Agency. Nutrient pollution: What you can do. Accessed 2021/06/11. URL: https://www.epa.gov/nutrientpollution/what-you-can-do. 
[17] Source Water Collaborative. Swc learning exchange: Why everyone should care about nutrient pollution. Accessed 2021/06/11. URL: $\quad$ https://sourcewatercollaborative.org/highlights/ swc-learning-exchange-why-everyone-should-care-about-nutrient-pollution/.

[18] Z Recebli, S Selimli, M Ozkaymak, and O Gonc. Biogas production from animal manure. Journal of Engineering Science and Technology, 10(6):722-729, 2015.

[19] Environmental and Energy Study Institute. Fact sheet - biogas: Converting waste to energy. Accessed 2021/06/04. URL: https://www.eesi.org/papers/view/ fact-sheet-biogasconverting-waste-to-energy.

[20] Dulce Celeste López-Díaz, Yicheng Hu, Winnie Chan, José María Ponce-Ortega, and Victor M. Zavala. Systems-level analysis of phosphorus flows in the dairy supply chain. ACS Sustainable Chemistry \& Engineering, 7(20):17074-17087, 2019. arXiv: https : / / doi .org/10.1021/ acssuschemeng.9b03129, doi:10.1021/acssuschemeng.9b03129.

[21] John D Wilson, Mike O'Boyle, and Ron Lehr. Monopsony behavior in the power generation market. The Electricity Journal,33(7):106804, 2020. doi:10.1016/j.tej.2020.106804.

[22] James Kuafman, Alice Roach, Jill Moreland, and Joe. Parcell. Biogas digestion: Economic and asset assessment for missouri. Technical report, 2020. URL: https://extension.missouri. edu/media/wysiwyg/Extensiondata/Pro/AgBusinessPolicyExtension/Docs/ MO-Biogas-Report.pdf.

[23] Ken Krich, Don Augenstein, JP Batmale, John Benemann, Brad Rutledge, and Dara Salour. Biomethane from Dairy Waste: A Sourcebook for the Production and Use of Renewable Natural Gas in California. 2005. URL: http://www.suscon.org/pdfs/cowpower/ biomethaneSourcebook/Chapter_8.pdf.

[24] Wisconsin Office of Energy Innovation. Wisconsn biogas survey report. Technical report, $610 \mathrm{~N}$ Whitney Way, 2nd Fl, Madison, WI 53707, 2011. URL: https://psc.wi.gov/Documents/ OEI/WisconsinBiogas SurveyReport.pdf.

[25] Gary Radloff. The biogas opportunity in wisconsin: 2011 strategic plan. Technical report, University of Wisconsin-Madison College of Agricultural and Life Sciences, 2011. URL: https://energy.wisc.edu/sites/default/files/Biogas_ Opportunity_in_Wisconsin_WEB.pdf.

[26] Essential Consulting Oregon. Oregon dairy digester feasibility study summary report. Technical report, 1328 W 2nd Avenue, Eugene, OR 97402, 2010. URL: http://www. oregonrenewables.com/Publications/Reports/OR_DairyBiogassummaryReport_ $100125 . p d f$.

[27] U.S. Environmental Protection Agency. Agstar data and trends. Accessed 2021/09/03. URL: https://www.epa.gov/agstar/agstar-data-and-trends. 
[28] Kerstine Appunn. Bioenergy - the troubled pillar of the energiewende, 2016. Accessed 2021/09/03. URL: https://www.cleanenergywire.org/dossiers/ bioenergy-germany.

[29] Ellen Thalman and Benjamin Wehrmann. What german households pay for power, 2020. Accessed 2021/09/07. URL: https://www.cleanenergywire.org/factsheets/ what-german-households-pay-power.

[30] Kerstine Appunn. What's new in germany's renewable energy act 2021, 2021. Accessed 2021/09/07. URL: https://www.cleanenergywire.org/factsheets/ whats-new-germanys-renewable-energy-act-2021.

[31] United States of America Federal Energy Regulatory Commission. Order no. 2222: Participation of distributed energy resource aggregations in markets operated by regional transmission organizations and independent system operators, 2020. URL: https://www.ferc.gov/sites/ default/files/2020-09/E-1_0.pdf.

[32] Midcontinent Independent System Operator. About miso. Accessed 2021/07/02. URL: https : //www.misoenergy.org/about/.

[33] Yicheng Hu, Matthew Scarborough, Horacio Aguirre-Villegas, Rebecca A. Larson, Daniel R. Noguera, and Victor M. Zavala. A supply chain framework for the analysis of the recovery of biogas and fatty acids from organic waste. ACS Sustainable Chemistry $\mathcal{E}$ Engineering, 6(5):6211-6222, 2018. arXiv:https: / / doi .org/10.1021/acssuschemeng. 7b04932, doi:10.1021/acssuschemeng.7b04932.

[34] Midcontinent Independent System Operator. Real-time pricing report. Accessed 2021/07/12. URL: https://www.misoenergy.org/markets-and-operations/ real-time--market-data/market-reports/\#nt=\%2FMarketReportType\% 3AReal-Time\%2FMarketReportName\%3AReal-Time\%20Pricing 20 Report\%20 (xls) $\& t=10 \& p=0 \& s=$ MarketReportPublished\&sd=desc.

[35] Richard S. J. Tol. The social cost of carbon: trends, outliers and catastrophes. Economics: the open-access, open-assessment E-journal, 2, 2008. doi:10.5018/economics-ejournal.ja. $2008-25$.

[36] William D Nordhaus. Revisiting the social cost of carbon. Proceedings of the National Academy of Sciences, 114(7):1518-1523, 2017. doi:10.1073/pnas . 1609244114.

[37] U.S. Energy Information Administration. Wisconsin state energy profile. Accessed 2020/05/21. URL: https://www.eia.gov/state/print.php?sid=WI.

[38] U.S. Energy Information Administration. How much carbon dioxide is produced per kilowatthour of u.s. electricity generation? Accessed 2021/05/28. URL: https: / / www . eia.gov/ tools $/$ faqs $/$ faq. php? id $=74$ \&t $=11$. 
[39] Apoorva M. Sampat, Andrea Hicks, Gerardo J. Ruiz-Mercado, and Victor M. Zavala. Valuing economic impact reductions of nutrient pollution from livestock waste. Resources, Conservation and Recycling, 164:105199, 2021. URL: https://www.sciencedirect.com/science/ article/pii/s0921344920305164, doi:https://doi.org/10.1016/j.resconrec. 2020.105199.

[40] David E. Kissel and Glendon Harris. Fertilizer recommendations by crops, categorized. Technical report, University of Georgia. URL: http://aesl.ces.uga.edu/publications/ soil/Cropsheets.pdf.

[41] RENEW Wisconsin. Bioenergy. Accessed 2021/03/22. URL: https://www . renewwisconsin.org/bioenergy/.

[42] Philip A. Tominac and Victor M. Zavala. Economic properties of multi-product supply chains. Comput Chem Eng, page 107157, 2020. URL: http://www.sciencedirect. com/science/article/pii/s0098135420305810, doi:https://doi.org/10.1016/ j.compchemeng.2020.107157.

[43] GP Renewables and LLC Trading. Wholesale power 101: Maximizing asset value and minimizing risk. Presentation. Accessed 2021/06/28. URL: https://www.epa.gov/sites/ production/files/2016-06/documents/09phillips_final.pdf.

[44] U.S. Federal Energy Regulatory Commission. Ferc order no. 2222: Fact sheet. Accessed 2020/12/8. URL: https://www.ferc.gov/media/ferc-order-no-2222-fact-sheet.

[45] Bahman Gharesifard, Tamer Başar, and Alejandro D Domínguez-García. Price-based coordinated aggregation of networked distributed energy resources. IEEE Transactions on Automatic Control, 61(10):2936-2946, 2015. doi:10.1109/TAC.2015.2504964.

[46] United States of America Federal Energy Regulatory Commission. Order no. 2222-a: Order addressing arguments raised on rehearing, setting aside prior order in part, and clarifying prior order in part, 2021. URL: https://www. ferc.gov/media/e-1-rm18-9-002.

[47] United States of America Federal Energy Regulatory Commission. Order no. 2222-b: Order addressing arguments raised on rehearing, setting aside in part and clarifying in part prior order, 2021. URL: https://www.ferc.gov/media/e-4-061721.

[48] U.S. Energy Information Administration. Wisconsin electricity profile 2019. Accessed 2021/05/28. URL: https://www.eia.gov/electricity/state/wisconsin/.

\section{Acknowledgments}

We acknowledge support from the U.S. Department of Agriculture (grant 2017-67003-26055). 


\section{Author Contributions}

E.D.E. and P.A.T. together developed the supply chain model conceptualizations and case studies for this paper. E.D.E. wrote the paper and created the figures, with revision and editing by P.A.T. and V.M.Z. The conceptual idea for the paper was the idea of V.M.Z. The FERC-2222 supplement is the work of E.D.E. with editing from P.A.T. and V.M.Z.

\section{Declaration of Competing Interest}

The authors declare that they have no competing interests, conflicts of interest, or personal ties that would influence or appear to influence the work in this paper. 